\title{
Internet Map Service for Environmental Health in the U.S.-Mexico Border Region
}

\begin{abstract}
Background: The border region of the United States and Mexico encompasses a vast and diverse array of physical settings and habitats that include wetlands, deserts, rangeland, mountains, and forests, which are unique in terms of the diversity of their water, mineral, and biological resources. The region is interconnected economically, politically, and socially owing to its binational heritage. In 1995, nearly 11 million people lived immediately adjacent to the border. By one account, that population could more than double by 2020 .
\end{abstract}

This rapid population growth and consequent economic development and landuse changes are pushing the limits of environmental sustainability and quality. Infrastructure development has lagged behind the rapid growth of the region, resulting in a shortage of water for municipal, agricultural, and industrial uses. These stressors threaten the quality of life in the region and raise concerns about the interdependence of environmental quality and human health.

To allow for continued economic growth while protecting the area's natural resources and fostering a high quality of life, the United States and Mexico need an improved understanding of the threats posed by these anthropogenic changes.

Issues of particular concern include (1) contaminants in ground water, surface water, and biota from agricultural, municipal, and industrial activities; (2) airborne pollutants from fossil-fuel combustion and other activities; (3) contaminants from past and present mining activities and mineral deposits; and (4) pathogens, pharmaceuticals, hormones, and other contaminants released in treated and untreated human and animal wastewaters.
Science Objective: The objective of this project is to provide an earth and biological resources database within a geographic framework using an Internet Map Service (IMS) to further our understanding of the linkages between the condition of the physical environment and public health issues. The IMS is now available on the Internet at borderhealth.cr.usgs.gov

Geographic Extent: The project is planned to ultimately encompass the entire U.S.-Mexico border region. However, initial efforts have focused on watersheds and aquifers along the Rio Grande/Rio Bravo below Falcon Reservoir to the lower part of the Laguna Madre of Texas and the nearshore parts of the Gulf of Mexico. The region encompasses 10,240 square miles-6,155 in Mexico and 4,085 in the United States. In Texas, the primary population centers are McAllen, Harlingen, and Brownsville; in Tamaulipas, they are Reynosa and Matamoros. Among the unique habitats of this segment of the international border region are the resacas (oxbow lakes) of the lower Rio Grande Valley. As in other border areas, the water resources and associated plants, fish, and wildlife of the

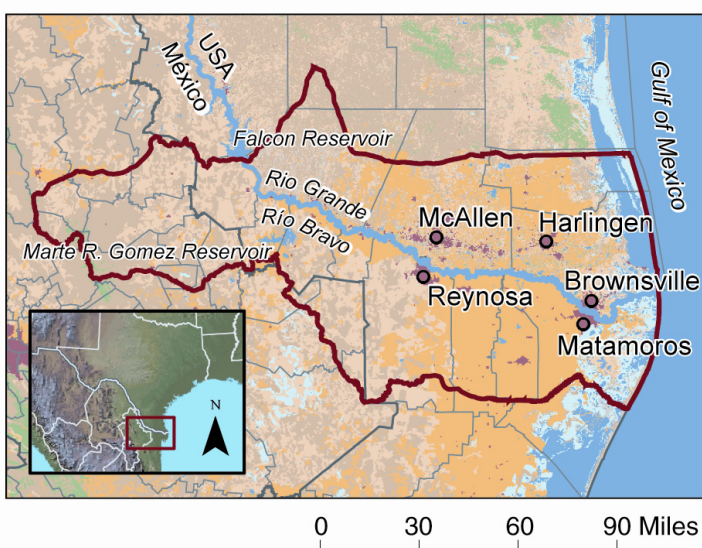

Figure 1. U.S.-Mexico Border Environmental Health Project study area. lower Rio Grande Valley are increasingly subject to the effects of human activities.

\section{Data Assimilation and Integration:} Through partnerships with local, State, and Federal agencies in both the United States and Mexico, the U.S. Geological Survey identified biologic, geologic, hydrologic, environmental, public health, and demographic datasets for incorporation into the binational IMS.

Scientific Utility of Data: To facilitate binational analysis of environmental issues concerning human health, major efforts have been made to seamlessly integrate U.S. and Mexico geospatial datasets along common themes. The procedures are documented in Federal Geographic Data Committee-compliant metadata files and can be applied to other areas along the U.S.-Mexico border.

Base cartographic data representing anthropogenic themes provide a locationbased foundation for analyzing the human interaction with the environment. Mapping the distribution of human modifications to the environment, such as transportation networks and manmade structural features, spatially narrows the hypothetical relations between potential urban con-

taminants and the environment. Demographic census data, health statistics, and various boundary datasets, such as county, census, and zip code boundaries, provide the information needed to study the statistical relations between reportable health incidences and population trends.

Landsat 7 Enhanced Thematic Mapper Plus (ETM+) medium resolution satellite data provide the ability to monitor regional landscape trends. To identify and map data at the local scale, 1-meter resolution digital orthophotos provide additional photo interpretation opportunities. Best-available elevation data, varying from 3.3- to 30-meter resolution, 


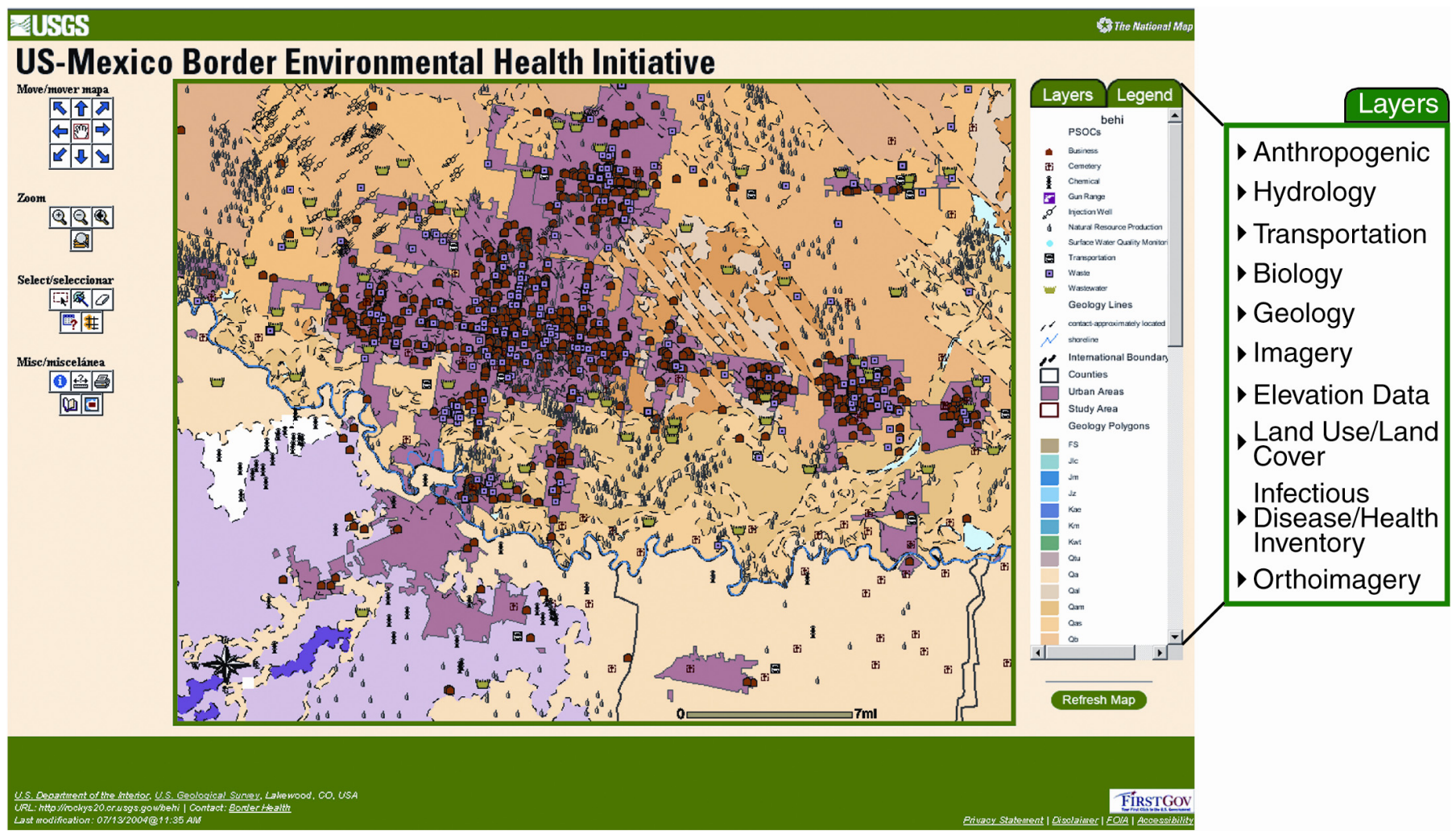

Figure 2. U.S.-Mexico Border Environmental Health Project IMS Web site with a view of potential sources of contamination (PSOCs) overlaid onto a binational geologic map of the McAllen and Reynosa urban areas.

provide a topographic base to evaluate flood inundations and to model air and water transport mechanisms such as slope relations, surface-water runoff, and water accumulations that might transport contaminants.

Geologic maps, soil maps, geochemical data from soil analyses, and geophysical data from aeromagnetic/radiometric surveys provide information on environmental contamination from naturally occurring toxic materials in soil and underlying rocks. These databases are important in defining the distribution and source of geologic materials. Distribution and source information are useful for establishing natural baseline occurrence and assessing environmental and healthrelated risks associated with selected geologic materials.

Binational hydrography data, such as where streams are located on the landscape in the United States and Mexico and where the streams are monitored for quality and quantity, provide information to facilitate our understanding of linkages between the physical environment and human disease. Ready access to these datasets will assist public health researchers in determining contaminants in ground and surface water and identifying pathogens, pesticides, pharmaceuticals, and hormones associated with human and animal waste. Development-related stressors, such as raw and under-treated sewage, pesticide exposure, toxic metals in sediment, and increasing salinities, are potential linkages in the U.S.-Mexico border area.

Geographic display of hydrologic data for the United States and Mexico allows resource managers to readily identify gaps in monitoring networks and provides visual information for future opportunities to begin more collaborative hydrologic monitoring. The geographic information system framework of these products improves the binational understanding of the occurrence and distribution of disease-causing agents in the environment and their exposure pathways in water, air, biota, and soil.

Data on the presence of environmental contaminants in water, aquatic sediments, and biota provide an indication of the nature and extent of anthropogenic pollution in the study area. The presence of toxic chemicals in the environment serves as a sentinel of environmental health and frequently has implications for public health.

\section{Opportunities for Collaborative}

Science: An anticipated outcome of this project will be increased opportunities for collaboration and communication among scientific researchers in the public health, natural resources, and environmental protection fields. Such collaborations could ultimately provide greater insight into the interdependence of environmental quality and human health and will assist in achieving the goal of a healthy border environment.

For more information, contact Denny Buckler, (573) 876-1803 dbuckler@usgs.gov or

Jim Stefanov, (512) 927-3543 jestefan@usgs.gov 